\title{
SUBPRODUTOS DE ABÓBORA COMO FONTE DE CAROTENOIDES E ANTIOXIDANTES
}

\author{
A. P. DALLA COSTA ${ }^{1}$, E. R.P. ROSSATTO, A.O.RIOS e S. H. FLÔRES ${ }^{2}$ \\ ${ }^{1}$ Universidade Federal do Rio Grande do Sul, Instituto de Ciência e Tecnologia de \\ Alimentos \\ ${ }^{2}$ Universidade Federal do Rio Grande do Sul, Instituto de Ciência e Tecnologia de \\ Alimentos \\ Email para contato: Simone.flores@ufrgs.br
}

\begin{abstract}
RESUMO - A utilização de subprodutos de vegetais é de grande importância devido as suas propriedades funcionais, tecnológicas e nutricionais, além de proteção ao meio ambiente e redução de custos para as indústrias. Este estudo teve como objetivo avaliar a qualidade da farinha de abóbora, obtida de seus subprodutos, como fonte de compostos bioativos. Os subprodutos de abóbora (cascas, aparas e sementes), obtidos da indústria de vegetais minimamente processados foram submetidos a secagem com o objetivo de obter-se uma farinha vegetal. A análise de antioxidantes da farinha obtida foi realizada pelo método DPPH (2,2-difenil-1-picrilhidrazilo) e os valores foram expressos em gramas de farinha / 100 gramas de DPPH. O perfil de carotenoides foi determinado em HPLC e os resultados foram expressos em $\mathrm{mg}$ de carotenoide / $100 \mathrm{~g}$ de farinha. Como resultado da análise de antioxidantes, $173,61 \mathrm{~g}$ de farinha de abóbora são necessárias para inibir $100 \mathrm{~g}$ de DPPH. Com a análise do perfil de carotenoides foram detectados picos de luteína $(2,52 \mathrm{mg})$, zeaxantina $(0,57$ $\mathrm{mg})$, alfa-caroteno $(0,28 \mathrm{mg}) \mathrm{e}$, destacando-se, beta-caroteno $(4,81 \mathrm{mg})$, com valores expressos para $100 \mathrm{~g}$ de farinha de abóbora. Através dos resultados obtidos é possível observar que os resíduos de abóbora podem ser utilizados como ingredientes na indústria, com o intuito de agregar compostos bioativos em produtos alimentícios.
\end{abstract}

\section{INTRODUÇÃO}

O aproveitamento de subprodutos é de grande interesse para a indústria de alimentos, devido a sua possibilidade de aplicação, como ingrediente, pelas suas propriedades funcionais, tecnológicas e nutricionais com benefícios para a saúde e com redução dos riscos de contaminação na indústria e no meio ambiente $\mathrm{e}$ consequentemente redução de custos (Schieber, Stintzing, Carle, 2001). Além disto, a utilização de partes de vegetais como cascas e sementes eleva a ingestão de fibras na dieta (Monteiro, 2009).

A abóbora (Cucurbita moschata, L.) faz parte da família Cucurbitaceae e possui destaque econômico importante, estando entre as 10 principais culturas vegetais em todo o mundo (Tadmor et al. 2005). Esta é cultivada devido a sua larga utilização para a nutrição humana, tanto pela sua polpa quanto por suas sementes, através do seu 
consumo direto ou para a elaboração de outras preparações, como xaropes, geléias, compotas e purês (Provesi, Dias e Amante, 2011).

O vegetal destaca-se por ser uma ótima fonte de carotenóides, principalmente de $\beta$-caroteno (que possui atividade pró-vitamina A), capaz de inibir radicais livres por sua ação antioxidante, propriedade que reduz os riscos câncer, aterosclerose e desordens coronarianas (Arruda et al., 2009; Padmaja, 2009; Ambrósio et al., 2006; Finley, 2005; Paula et al., 2004).

Assim, este estudo teve como objetivo avaliar a qualidade farinha de abóbora, obtida de seus subprodutos, como fonte de compostos bioativos.

\section{MATERIAL E MÉTODOS}

\subsection{Obtenção da Farinha Vegetal}

Os subprodutos de abóbora (casca, aparas e semente), obtidos da indústria de vegetais minimamente processados foram submetidos a secagem com o objetivo de se obter uma farinha vegetal.

Os subprodutos foram higienizados em água corrente, clorados a 200 ppm por 15 minutos, centrifugados em centrífuga de $100 \mathrm{xg}$ (desenvolvido no laboratório de Pós Colheita da Faculdade de Agronomia da UFRGS) e secos em estufa (DeLeo, modelo B5AFD, Brasil) a $55{ }^{\circ} \mathrm{C}$ por 20 horas. Posteriormente o material foi triturado em moinho (Arbel, modelo MCF55, Brasil).

| A fibra vegetal obtida foi peneirada em peneiras específicas de 35 mesh_(Bertel, Brasil) para obtenção de farinha.

\subsection{Atividade Antioxidante (DPPH)}

A metodologia é baseada no sequestro do radical 10 2,2- difenil - 1 picrilhidrazilo (DPPH), usado para determinar a atividade antioxidante (Brand-Williams et al., 1995).

As leituras foram feitas em espectrofotômetro a 515 nm, após 40 minutos.

Os resultados são expressos como a concentração do antioxidante requerido para reduzir a quantidade original de radicais livres, por 50\% (EC50), e os valores são apresentados em gramas de fruto / grama de DPPH e em percentual de inibição do radical DPPH, através da equação abaixo:

$$
\begin{aligned}
& \% \text { Inibição }=100-\left[\left(\mathrm{Abs}_{\text {amostra }}-\mathrm{AbS}_{\text {branco }}\right) \times 100\right] \\
& \mathrm{Abs}_{\text {controle }}
\end{aligned}
$$




\subsection{Perfil de Carotenóides}

O extrato de carotenóides foi preparado de acordo com Mercadante, Britton e Rodriguez-Amaya (1998). As etapas principais são: extração dos pigmentos com acetona e saponificação com metanol $10 \% \mathrm{KOH}$. Após a remoção do álcali, o extrato foi concentrado em evaporador rotativo (Fisatom, Modelo 801) $\left(\mathrm{T}<25^{\circ} \mathrm{C}\right)$.

O extrato concentrado foi diluído em $2 \mathrm{ml}$ de éter terc-metil-butílico (MTBE- J. T. Baker., Cas. number 1634-04-4, pureza 99,96\%), colocado em ultrasom (Unique, modelo USC 1400) por 1 minuto e filtrado em filtro (Millex LCR 0,45 $\mu \mathrm{m}, 13 \mathrm{~mm}$ ). A análise por HPLC foi realizada em um equipamento Agilent 1100 Series HPLC equipado com um sistema de bombas de solvente quaternário (Waters Série 2695) e um detector de UV / Vis ( Waters 2487 dual Series I) . Foi utilizada uma coluna (YMC, Japão) polimérica C30 de fase reversa $(250 \mathrm{~mm}$ x 4,6 mm, $3 \mu \mathrm{m})$. O comprimento de onda foi ajustado para $450 \mathrm{~nm}$. A fase móvel foi água:metanol:éter metil- terc - butílico (MTBE) (JTBaker - Mallinckrodt, EUA) a partir de 5:90:5, atingindo 0:95:5 em $12 \mathrm{~min}$, 0:89:11 em 25 min, 0:75:25 em 40 min e, finalmente, 00:50:50 depois de um total de 60 min, com uma taxa de fluxo de $1 \mathrm{~mL} / \min$ a $33^{\circ} \mathrm{C}$ (Zanatta \& Mercadante, 2007).

Os carotenóides foram quantificadas utilizando-se curvas padrão de luteína (1-65 $\mathrm{mg} / \mathrm{L}), \mathrm{mg} / \mathrm{L}$ ), criptoxantina (4-100 mg/L) , $\alpha$-caroteno (2-25 mg/L) e $\beta$-caroteno (5-50 $\mathrm{mg} / \mathrm{L}$ ). Os carotenóides $\beta$-criptoxantina (pureza $>97 \%$ ), $\beta$-caroteno (pureza $>93 \%$ ) , $\alpha$ caroteno (pureza $>95 \%$ ) e zeaxantina (pureza $>95 \%$ ) foram adquiridos da Sigma Chemical (EUA). Luteina (pureza $>95 \%$ ) foi adquirido a partir de Indofine Chemical Company Inc. Hillsborough (EUA). Os resultados foram expressos em mg por $100 \mathrm{~g}$ de amostra seca.

A identificação foi efetuada por comparação dos tempos de retenção dos picos da amostra e do controle, nas mesmas condições.

\section{RESULTADOS E DISCUSSÃO}

\subsection{Atividade Antioxidante (DPPH)}

Como resultado da análise de antioxidantes, 173,61g de farinha de abóbora são necessárias para inibir 100g de DPPH. Em percentual, o resultado obtido corresponde a $60 \%$ de inibição do radical DPPH.

Resultado semelhante foi encontrado por Saavedra et al. (2013), analisando subprodutos de abóbora (cascas e sementes) - 70\% e 49\% respectivamente, mostrando um percentual de inibição relevante, e assim sugerindo uma boa atuação dos subprodutos de abóbora como fonte antioxidante.

Vulic et al., (2012) analisando a capacidade antioxidante de um extrato feito com 
bagaço de beterraba, encontrou um percentual de inibição superior $(82,3 \%)$ através da análise com radical DPPH. Este resultado sugere que a produção de um extrato pode ser mais eficaz do que a elaboração de uma farinha para a retenção de compostos antioxidantes, provavelmente por excluir a etapa de altas temperaturas na secagem que esta última exige.

\subsection{Perfil de Carotenoides}

Com a análise do perfil de carotenoides, 4 foram encontrados em predominância: luteína, zeaxantina, $\alpha$-caroteno e $\beta$-caroteno. Outros compostos foram detectados em baixas concentrações. Como esperado, o carotenoide com maior expressão foi o $\beta$-caroteno, como pode ser observado na Tabela 1.

Tabela 1 - Identificação do perfil de carotenoides em farinha de abóbora

\begin{tabular}{cccc}
\hline \multicolumn{4}{c}{ CAROTENOIDES - Concentração $(\mathrm{mg} / 100 \mathrm{~g}$ de farinha de abóbora $)$} \\
\hline Luteína & Zeaxantina & $\alpha$-caroteno & $\beta$-caroteno \\
$2,52 \pm 0,01$ & $0,57 \pm 0,001$ & $0,28 \pm 0,001$ & $4,81 \pm 0,02$ \\
\hline
\end{tabular}

Médias e desvios-padrão de análises em triplicata.

Provesi, Dias e Amante (2005) encontraram resultados semelhantes quando analisaram o perfil de carotenóides das abóboras Cucurbita moschata e Cucurbita maxima, tendo como majoritário igualmente o $\beta$-caroteno.

Em estudo realizado com subprodutos de laranja (Crizel et al., 2013), foi obtida uma farinha com casca, bagaço e sementes da fruta para uso como substituto de gordura. Através da análise do conteúdo de carotenoides os autores encontraram valores para luteína $(0,47 \mathrm{mg} / 100 \mathrm{~g})$, zeaxantina $(0,04 \mathrm{mg} / 100 \mathrm{~g}), \alpha$-caroteno $(0,13$ $\mathrm{mg} / 100 \mathrm{~g})$ e $\beta$-caroteno $(0,20 \mathrm{mg} / 100 \mathrm{~g})$. Estes valores mostram-se inferiores quando comparados com os resultados obtidos neste trabalho com os subprodutos de abóbora, sugerindo assim que os resíduos deste vegetal podem ter um melhor aproveitamento como fonte de carotenoides.

\section{CONCLUSÃO}

Através dos resultados obtidos é possível observar que é viável a transformação dos resíduos de abóbora em farinha e assim, esta pode ser utilizada como ingrediente na indústria, com o intuito de agregar compostos bioativos em produtos alimentícios. 


\section{REFERÊNCIAS}

AMBRÓSIO, C. L. B.; CAMPOS, F. A. C. S.; FARO, Z. P. de. Aceitabilidade de flocos desidratados de abóbora. Revista de Nutrição, Campinas, v.19, n.1, p.39-45, jan.fev./2006.

ARRUDA, S. F.; SIQUEIRA, E. M. D. A.; DE VALÊNCIA, F. F. Vitamin A deficiency increases hepcidin expression and oxidative stress in rat. Nutrition, v.25, n.4, p. $472-478,2009$.

BRAND-WILIAMS, W.; CUVELIER, M. E.; BERSET, C. Use of a free radical method to evaluate antioxidant activity. Food Science and Technology, v.28, p.25-30. 1995

CRIZEL,T. M.; JABLONSKI, A.; RIOS, A. O.; RECH, R.; FLÔRES, S. H. Dietary fiber from orange byproducts as a potential fat replacer. Food Science and Technology. V. 53, n.1, p. 9-14. 2013.

FINLEY, J. W. Proposed criteria for assessing the efficacy of cancer reduction by plant foods enriched in carotenoids, glucosinolates, pholyphenols and selenocompounds. Annals of Botany, n.95, p.1075-1096, 2005.

MONTEIRO, B. A. Valor nutricional de partes convencionais e não convencionais de frutas e hortaliças. Fevereiro, 2009. 62p. Dissertação (Mestrado em Agronomia Energia na Agricultura) - Universidade Estadual Paulista. Faculdade de Ciências Agronômicas, Botucatu, 2009.

PADMAJA, G. Uses and nutritional data of sweet potato. The sweet potato. Biomedical and Life Sciences, p.189-234, 2009.

PAULA, T. P.; PERES, W. A. F.; CARMO, M. G. T. B. Os carotenoides no tratamento e prevenção do câncer. Revista Brasileira de Nutrição Clínica, v.19, n.2, p.100-108, 2004.

PROVESI, J. G.; DIAS, C. O.; AMANTE E. R. Changes in carotenoids during processing and storage of pumpkin puree. Food Chemistry. v. 128, p. 195-202. 2011.

SAAVEDRA, M. J.; AIRES, A.; DIAS, C.; ALMEIDA, J. A.; DE VASCONCELOS, M. C. B. M.; SANTOS, P.; ROSA, E. A.. Evaluation of the potential of squash pumpkin by-products (seeds and shell) as sources of antioxidant and bioactive compounds. Journal of Food Science and Technology. 2013.

SCHIEBER, C.; STINTZING, F. C.; CARLE, R. By-products of plant food processing as a source of functional compounds - recent developments. Trend in Food Science \& Technology, v. 12, p.401-413, 2001.

TADMOR, Y.; PARIS, H. S.; MEIR, A.; SCHAFFER, A. A.; LEWINSOHN, E.. Dual role of the pigmentation gene $\mathrm{B}$ in affecting carotenoid and vitamin $\mathrm{E}$ content in squash 
(cucurbita pepo) mesocarp. Journal of Agricultural and Food Chemistry. v. 53. p.975963. 2005.

VULIC, J.; CANADANOVIC-BRUNET, J.; CETKOVIC, G.; TUMBAS, V.; DJILAS, S.; CETOJEVIC-SIMIN, D.; CANADANOVIC, V. Antioxidant and cell growth activities of beet root pomace extracts. Journal of Functional Foods. v.4, p. 670-8. 2012.

ZANATTA, C. F.; MERCADANTE, A. Z. Carotenoid composition from the Brazilian tropical fruit camu-camu (Myrciaria dubia). Food Chemistry, v.. 101, p. 1526-32. 2007. 